\title{
Internal and basal ice changes near the grounding line derived from radio-echo sounding
}

\author{
SEIHO URATSLKA \\ Communicalions Research Laboratory, 4-2-1, Vikui-hïamachi, Koganei-shi. Tokyo 184, Japan \\ Fumhiko Nishio \\ Hokkaido University of Education, 1-15-55. Shiroyama, Kushiro 085, Japan \\ SHINJI MAe: \\ Hokkaido University, Kïla-13, Vishi-o, Kïla-ku, Sapporo 060, Japan
}

\begin{abstract}
Evidence of changing basal and internal ice properties near the grounding line was derived from airborne radio-echo-sounder observations of the ice sheet around the Sor Rondane Mountains, Antarctica. From the trailing figure of the bottom-echo signal, the roughness of the ice bottom near the grounding line was inferred. Results show that the specular components of scattering begin to appear on the ice-shelf side of the grounding line. Furthermore, double-trip echoes were observed with a strong scattering in the shelf area, and their boundary of occurrence was very close to the grounding line. This is evidence of interaction between ice and sea water at the bottom of the ice shelf. We also examined the occurrence of internal lavered echoes. In most of the area around the mountains, internal echoes were observed continuously, but they were not found at or close to the ice shelf. The boundary between the appearance and disappearance of internal-layer echoes is distinct, and occurs $2030 \mathrm{~km}$ inland from the grounding line. These results suggest that some major change may occur in the internal ice on the inland side of the grounding line.
\end{abstract}

\section{INTRODUCTION}

Most of the Antarctic coast is covered by ice shelves comprising about $11 \%$ of the total area of Antarctica. In the transitional area between an ice shelf and an ice sheet. changes of ice property are expected to occur in the bottom and internal ice. The grounding line is defined as the boundary at which the ice bottom changes contact from rock to sea water, and it divides the ice shelf from the ice shect. Clanges in the ice-bottom property occur at the grounding line because of the interaction between ice and sea water. Accurate determination of the grounding-line position is necessary not only for predicting likely icesheet and ice-shelf responses to changes in climate, but also for understanding internal ice physics in this transitional area. Airborne radar observation, as well as being a useful way to examine the ice-bottom topography, can also be used to diagnose physical properties of the ice sheet. To determine the position of the grounding line, methods using a radio-echo sounder have been used, for example, a hydrostatic-balance equation using surface and bottom topography, amplitude change of the bottom echo (Jacobel and others, 1994), and measuring the radio scattering strength at the bottom of the ice Nishio and Uratsuka, 1991). However, calculation of the scattering strength is easily affected by other parameters, especially what values in the ice are used for the attenuation coeflicient, and data including many spikes. We previously reported an algorithm for inferring dependence of scattering at the bottom of the ice on the angle of incidence. Preliminary results of this analysis showed that smooth bottom features were observed in the ice-shelf area far from the grounding line Lratsuka and others, 1989). This paper shows that the incidence-angle dependence of scattering coefficients at the bottom measured by radio-echo sounding confirms that the position of the grounding line can be determined by detecting different degrees of bottom roughness. This method complements the method of detecting differences in the scattering strength caused by different underlying materials.

Some work based on ice-core samples provided valuable information on vertical changes in internal structure such as three sources of the internal mass of the ice shelf: the accumulation of snow in this area, ice from the upstream ice sheet, and frozen sea water Wakahama and Budd, 1976; Oerter and others, 1992). A wider survey is necessary to understand how the internal structure of the ice shelf will be modified and the dynamics at the transitional region near the grounding line. Scattering detected by a radio-echo sounder can be used to examine internal ice structure. In most areas of the ice sheet, internal layer echoes that indicate the internal stratigraphy of the ice sheet are observed by 
radio-echo sounding. We analyzed the occurrence of these internal laver echoes and found that the areas where they are absent are concentrated at or close to the ice shelf.

\section{RADIO-ECHO-SOUNDER OBSERVATION}

The Sor Rondane Mountains are located at about 20 $30^{\circ} \mathrm{E}, 71-73^{\circ} \mathrm{S}$ in east Antarctica. There is an ice shelf about $100 \mathrm{~km}$ north of the Sor Rondane Mountains, whereas the southern side of the mountains is about $2000 \mathrm{~m}$ above sea level; thus the altitude of the mountainous ice sheet along a north south line changes by about $2000 \mathrm{~m}$. Figure 1 is a map of the topography of this area with the flight lines taken for airborne radioccho-sounding measurement. Observation with a $179 \mathrm{MHz}$ airborne radio-echo sounder was carried out in the austral summer of 1986 by the 27 th Japanese Antarctic Research Expedition (JARE-27). Specifications of the radar are shown in Table 1 . The resolution of the radar can be changed by choosing from three different pulse widths, and most of the observations used a $250 \mathrm{~ns}$ pulse $21 \mathrm{~m}$ resolution in ice). The radar was able to measure ice up to $2500 \mathrm{~m}$ thick. Digital data were accumulated with an on-board 0.25 in $(0.63 \mathrm{~cm})$ cassette recorder, along with the aircraft navigation data: Omega and GPS (position), radio and pressure altimeter (altitude) and gyroscope (attitude). A more detailed description of the radar system is given by Uratsuka and others (1989).

\section{BOTTOM SCATTERING CHARACTERISTICS}

\section{Bottom scattering characteristics in the ice shelf}

The bottom features of ice shelves are very important for understanding the mass balance of ice sheets (Thomas, 1979) because ice and sea water interact at the ice-shelf
Table 1. Specifications of the radio-echo sounder

\begin{tabular}{lll}
\hline Transmitter & Frequency & $179 \mathrm{MHz}$ \\
& Peak power & $1 \mathrm{~kW}$ \\
& Pulse width & $60 / 250 / 1000 \mathrm{~ns}$ \\
& PRF & $1 \mathrm{kHz}$ \\
Receiver & Sensitivity & $-110 \mathrm{dBm}$ \\
& Noise figure & $1 \mathrm{~dB}$ \\
Antenna & Type & 3 element Yagi \\
& Gain & $8.15 \mathrm{dBi}$ \\
& Beam width & $70^{\circ}$
\end{tabular}

Resolution in ice $5 / 21 / 84 \mathrm{~m}$

bottom (Morgan, 1972). In particular, the roughness of the ice-shelf bottom is an indication of the interaction between ice and sea water. Neal (1979) investigated the smoothness of the bottom of the Ross Ice Shelf using an "ESM recording" of radio-echo sounding. Other research investigating bottom features of ice shelves by radio-echo sounding has also been reported (Shabtaie and others, 1987; Jenkins and Doake, 1991). These reports discuss the reflection coefficient from bottom echoes. Generally, the scattering coefficient, which is defined in radar equations (e.g. Ulaby and others, 1982), is used for discussing the properties of the target plane. The scattering coefficient describes the effects of both boundary roughness and differences in the medium below the ice, and is dependent on the incidence angle. If the target plane is very smooth comparable to the radar wavelength, the scattering will be specular and the incidence-angle dependence will be restricted in the small incidence-angle range. In the extreme case of a smooth surface, the reflection coefficient calculated in the equation in, for example, Shabtaie and others (1987) is approximately the same one defined in plane-wave theory, and independent of the radar pulse

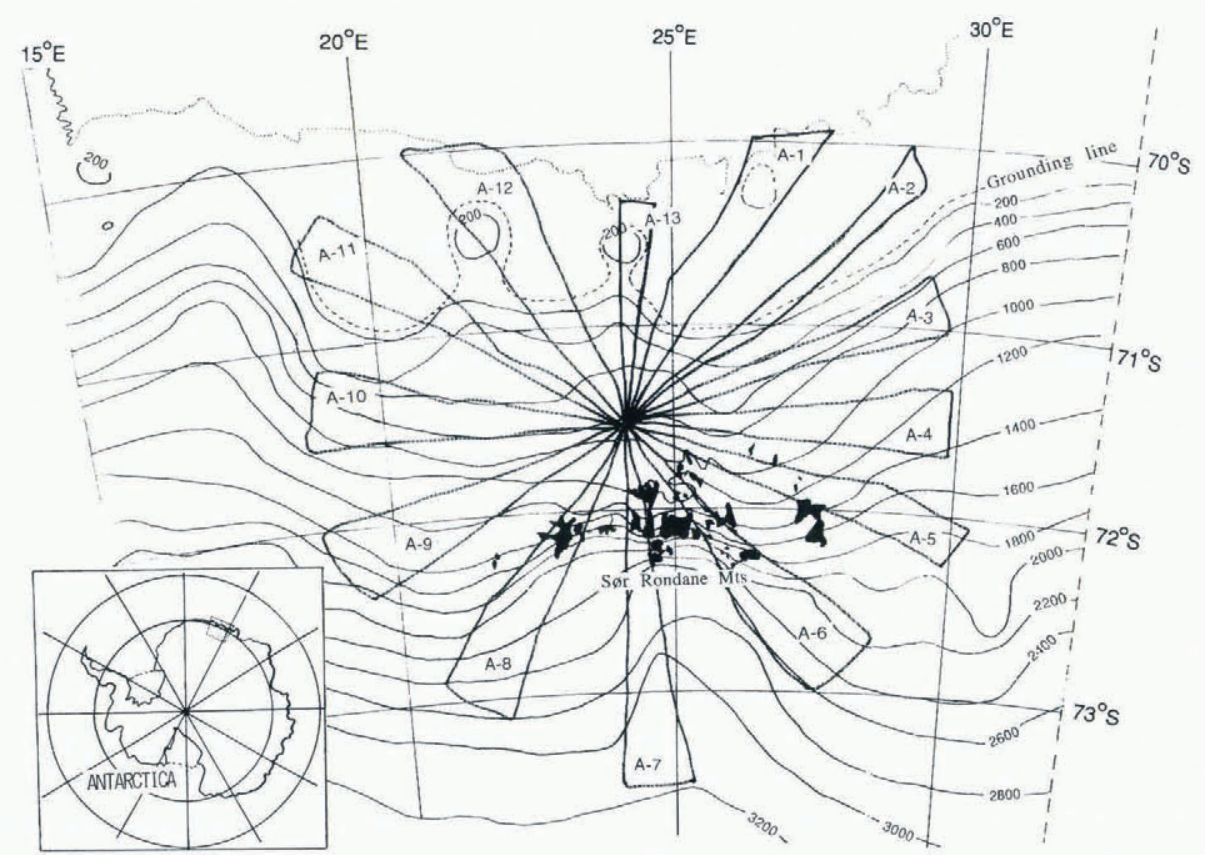

Fig. 1. Surface topography and flight lines of radio-echo-sounding observations around the Sor Rondane Mountains. 
width. The Fraunhofer criterion shown below is a more quantitative indicator of specular scattering Ulaby and others, 1982):

$$
\Delta h<\frac{\lambda}{32 \cos \theta}
$$

where $\theta$ is the incidence angle, $\lambda$ is the wavelength, and $\Delta h$ is the root-mean-square height deviation. Assuming a $179 \mathrm{MHz}$ frequency, the mean roughness value of the Fraunhofer criterion is less than about $5 \mathrm{~cm}$ in the nadir direction. As a larger deviation of $\Delta h$ is possible in the area illuminated by the same pulse-range gate, it is better to use scattering coefficients defined from a radar equation rather than as reflection coefficients.

When the radar system has a wide antenna-beam pattern rather than a pulse-illuminated area, the echo shape formed by the scattering signal is strongly dependent on the incidence angle. The incidence angle can be calculated from the delay time, and the scattering coefficient can be inferred using an appropriate radar equation. In the case of an ice sheet, the radar equation should include the effect of refraction at the air/ice interface. Uratsuka and others (1989) proposed a radar equation which satisfies the above conditions, as follows:

$$
P_{\mathrm{r}}=\frac{P_{\mathrm{t}} G^{2} \lambda^{2} c \tau \sigma^{o}\left(\theta_{2}\right) f^{2}\left(\theta_{1}\right) \cos ^{3} \theta_{1}}{2^{6} \pi^{2} L^{2}\left(H+\frac{z}{m \xi^{2}}\right)\left(H+\frac{z}{m \xi^{i / 3}}\right)^{2} \xi^{-2}} \exp (-2 z / \delta) .
$$

Here, $\sigma^{\circ}$ is the scattering coefficient of the incidence angle at the ice-sheet bottom, $n$ is the refractive index, $z$ is the ice thickness, and $\theta_{2}$ is the refractive angle equal to the incidence angle at the bottom), which through Snell's law is related to $\theta_{1}$, the angle of incidence on the surface. We define $\xi$ as $\xi=\cos \theta_{2} / \cos \theta_{1}$.

In addition, these geometrical parameters should be related to the delay time $t$ as follows:

$$
c t=\frac{H}{\cos \theta_{1}}+\frac{n z}{\cos \theta_{2}} \text {. }
$$

Other parameters are defined as follows: $P_{\mathrm{r}}$ is received power; $P_{\mathrm{t}}$ is transmitted power; $G$ is antenna peak gain; $f\left(\theta_{1}\right)$ is normalized antenna pattern; $\lambda$ is wavelength $(=1.67 \mathrm{~m}) ; \tau$ is pulse width; $c$ is light speed; $\delta$ is penetration depth; $H$ is airplane altitude; $L$ is system loss.

Uratsuka and others 1990 reported the incidenceangle dependence of scattering coefficients along a flight line in the ice-shelf area and concluded that specular scattering, inferred by the incidence-angle dependence of the scattering coefficient, increases with distance from the grounding line. Here, we examine differences in the smoothness of a grounded ice bottom and a floating ice bottom very close to the grounding line.

\section{Bottom scattering characteristics near the ground- ing line}

A tentative grounding line is shown as the dashed line in Figure 1. This line was determined by comparing the icebottom topography measured by a sounder and calculated by the hydrostatic equation:

$$
h=0.1241 d
$$

where $d$ is the inferred ice thickness and $h$ is the measured elevation of the ice surface above sea level Nishio and Uratsuka, 1991). Scattering coefficients that are within $1 \mathrm{~km}$ of this tentative grounding line on the inland and ice-shelf sides are plotted in Figure 2. These plots are derived from Equations (2) and (3), using the data from the A-1, -2, -11, -12 and -13 flight lines shown in Figure 1. As Figure 2 shows, the scattering features from the inlandice side and from the ice-shelf floating-ice) side are typically different. In the incidence-angle range of 10 $20^{\circ}$, scattering coeflicients of ice from the inland side are $510 \mathrm{~dB}$ greater than those of floating ice. In this analysis, we did not calculate the scattering coefficients at incidence angles of less than $10^{\circ}$ because then the scattering signals arrived at the receiver simultaneously. The values of the scattering coefficients are sensitive to the attenuation coeflicients and these are assumed to be constant in depth. Nishio and Uratsuka (1991) discussed the relationship between the grounding line and the scattering coefficients at the nadir incidence $\sigma^{\circ}(0)$ : mean value at incidence angles of $0-10^{\circ}$ ) of the ice-shelf bottom along a flight line (A-13) using Equations (2) and (3). They showed that $\sigma^{o}(0)$ of floating ice is about $1020 \mathrm{~dB}$ higher than that of inland ice. This difference may be caused mainly by the differences in media: rock or water. The position of the grounding line determined by Equation (4) agreed with that determined by radar analysis to within a few kilometers. Based on this, we
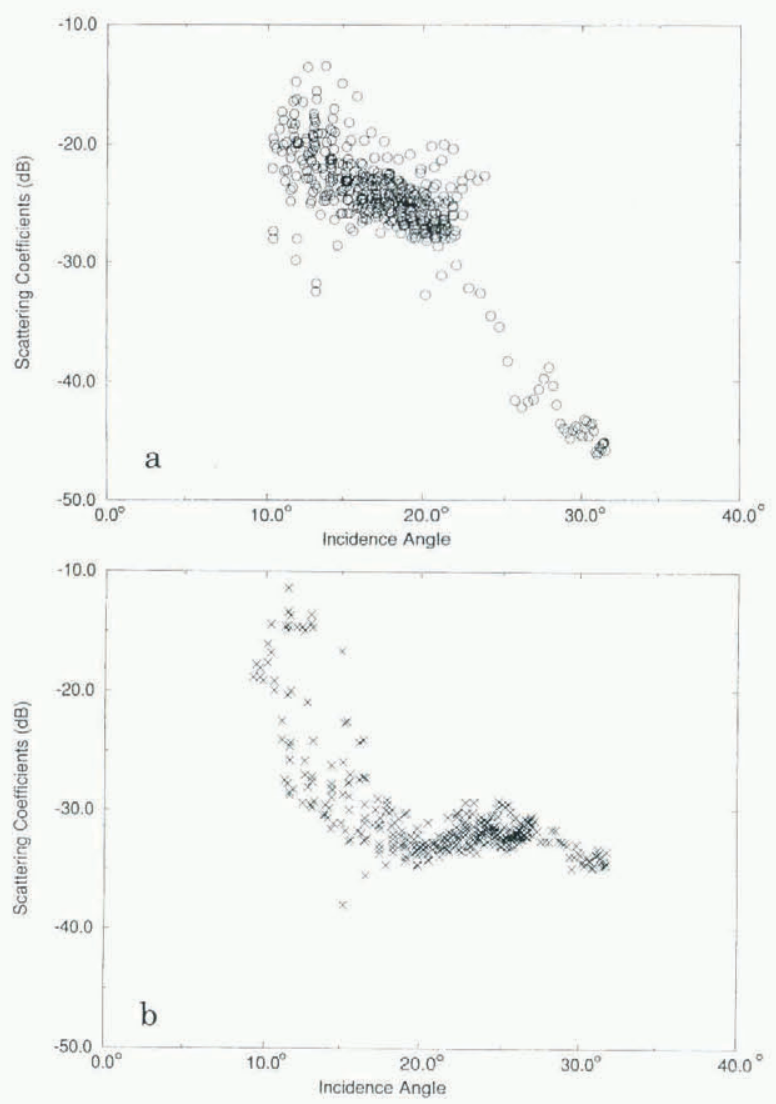

Fig. 2. Incidence-angle dependencies of scallering coefficients near grounding line delermined using Equations (2) and (3). Upper panel (a) summarizes the dala from a zone $1 \mathrm{~km}$ inland of the grounding line. Lower panel (b) summarizes the data from a zone $1 \mathrm{~km}$ on the ice-shelf side of the grounding line. 
suggested that scattering coefficients are a good indicator of the position of the grounding line. However, the distribution of scattering coefficients along a flight line includes many spikes, which are caused primarily by error in the inferred attenuation coefficient. Figure 2 confirms that differences in the ice bottom exist not only in terms of the contrasting material but also in terms of roughness. Information from scattering in the nadir direction $\sigma^{\circ}(0)$ and the incidence angle dependence $\sigma^{\circ}(\theta)$ is complementary. Combining this and our present results shown in Figure 2 suggests a very steep dependence of the the scattering coefficient on the incidence angle in the range $0-20^{\circ}$. These results suggest that a boundary of strongly specular scattering exists very close to the grounding line.

\section{Double-trip echoes}

On the ice shelf, double-trip scattering echoes were often observed. Double-trip echoes occur when the pulse reflects twice from the ice/water interface and once from the ice/air interface. Double-trip echoes are indicative of relatively low power loss due to attenuation in the ice and/or specular scattering. As shown in Figure 3, doubletrip echoes are observed only on the ice-shelf area, and their appearance begins at the grounding line in some observations. Though the bottom part of the ice shelf consists of saline ice which attenuates radio waves, radar reflections are stronger there. This strong signal appears to be due to specular scattering. These results are consistent with Uratsuka and others $(1990)$ and Nishio and Uratsuka (1991).

\section{OCGURRENGE OF INTERNAL-LAYERED ECHOES}

A differential filtered Z scope (DFZ) is very useful for studying the layered echoes within internal ice. The DFZ image is produced using the first derivative of the received power against the vertical distance. In about $70 \%$ of our observations, internal layers are detected using DFZ images. This filter process clearly shows the peaks of echoes and reduces the wide dynamic range of a radar signal to a limited dynamic range for display. As such, these filtering effects emphasize the leading edge of echoes, but the strength of an image is no longer proportional to the scattering strength. It is important to take these filter effects into account when discussing the occurrence of internal-layer echoes detected by DFZ images. To avoid confusion due to terminology, we define the "internal layer" as a physical layer of ice, the "internal echo" as the echo signal from internal ice, the "layered echo" and "internal-layered echo" as layered characteristics in the internal echo, and the "DFZ image" as the differential filtered image between the ice-surface echo and the ice-bottom echo. We have to distinguish strictly between the layered echo and the layered pattern which is shown by DF7, because in some cases the layered pattern shown results from a mixture of internal ice and surface features that originate in the same range gates owing to the wide beam antenna of the radar system.

\section{Classification of DFZ images}

To avoid being misled by instrumental disturbances, filtering effects or confusing surface echoes, we classified the DFZ images into four categories according to their layered pattern, echo strength and other characteristics. Type $A$ is assigned when typical layer echoes exist. As shown in Figure 4a, the layer pattern is continuous and the echoes occur at regular intervals. Type B is assigned in a less typical case, though internal echoes can be distinguished from other echoes as shown in Figure $4 \mathrm{~b}$. This case includes echoes which are not always multiplelayered or stratified, but obviously have internal causes. An example of type $\mathrm{C}$ is shown in Figure $4 \mathrm{c}$ where it is

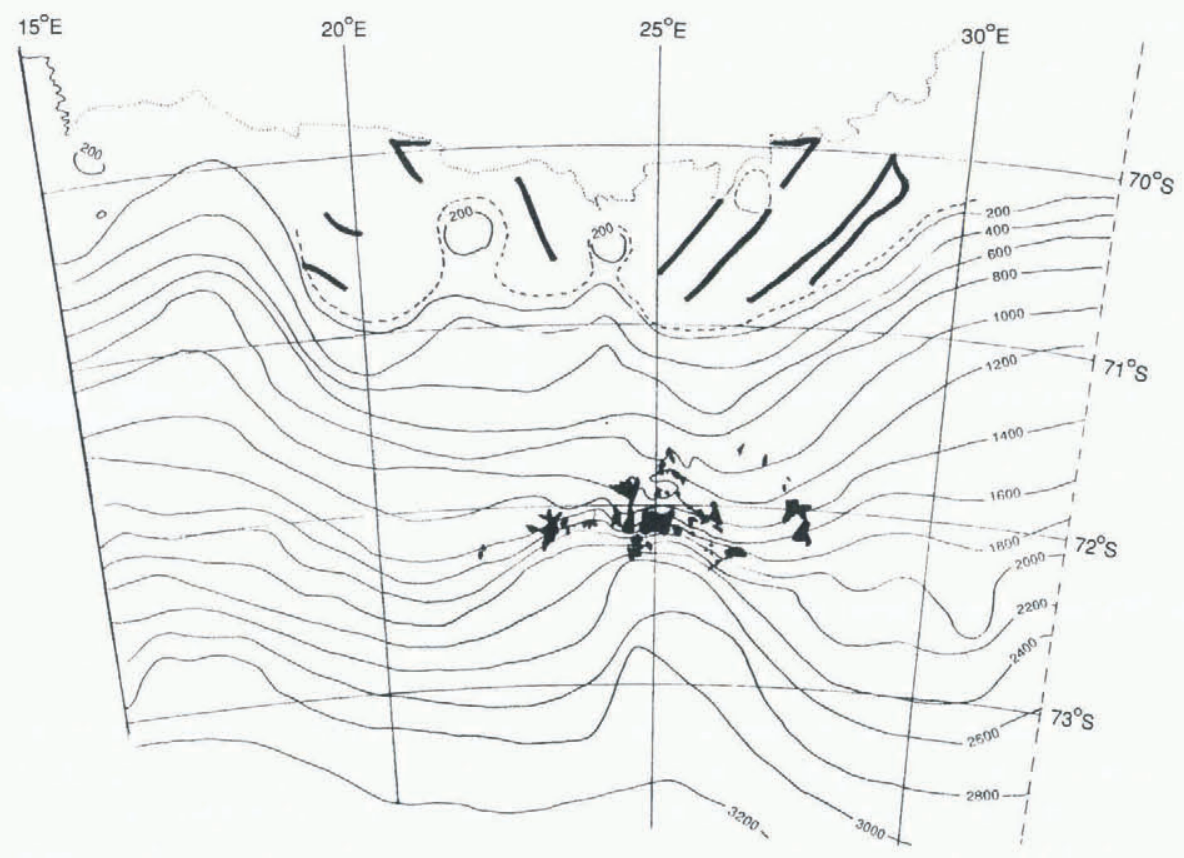

Fig. 3. Appearance of double-trip echoes: thick lines indicate occurrence and duration of the double-trip echoes along the flight line. 

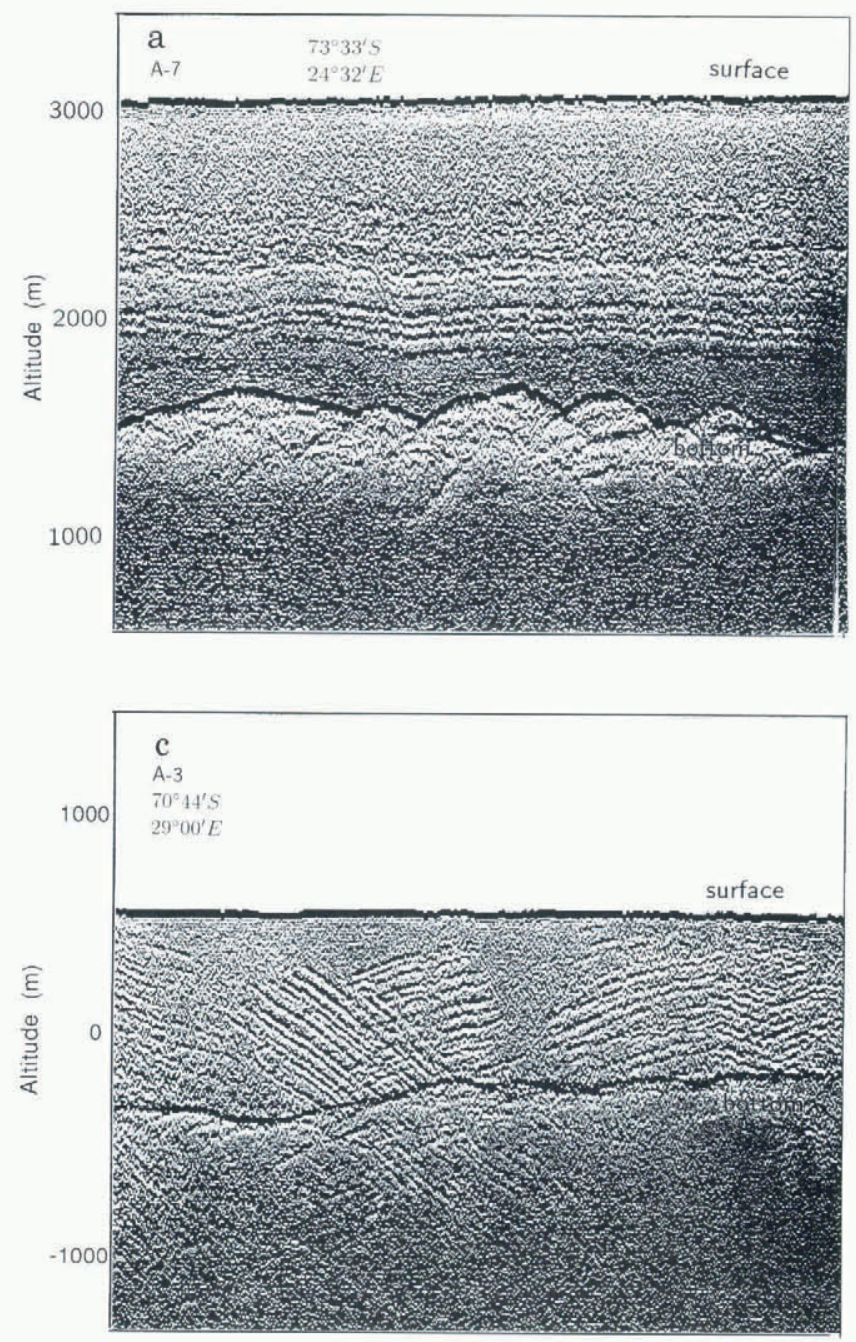
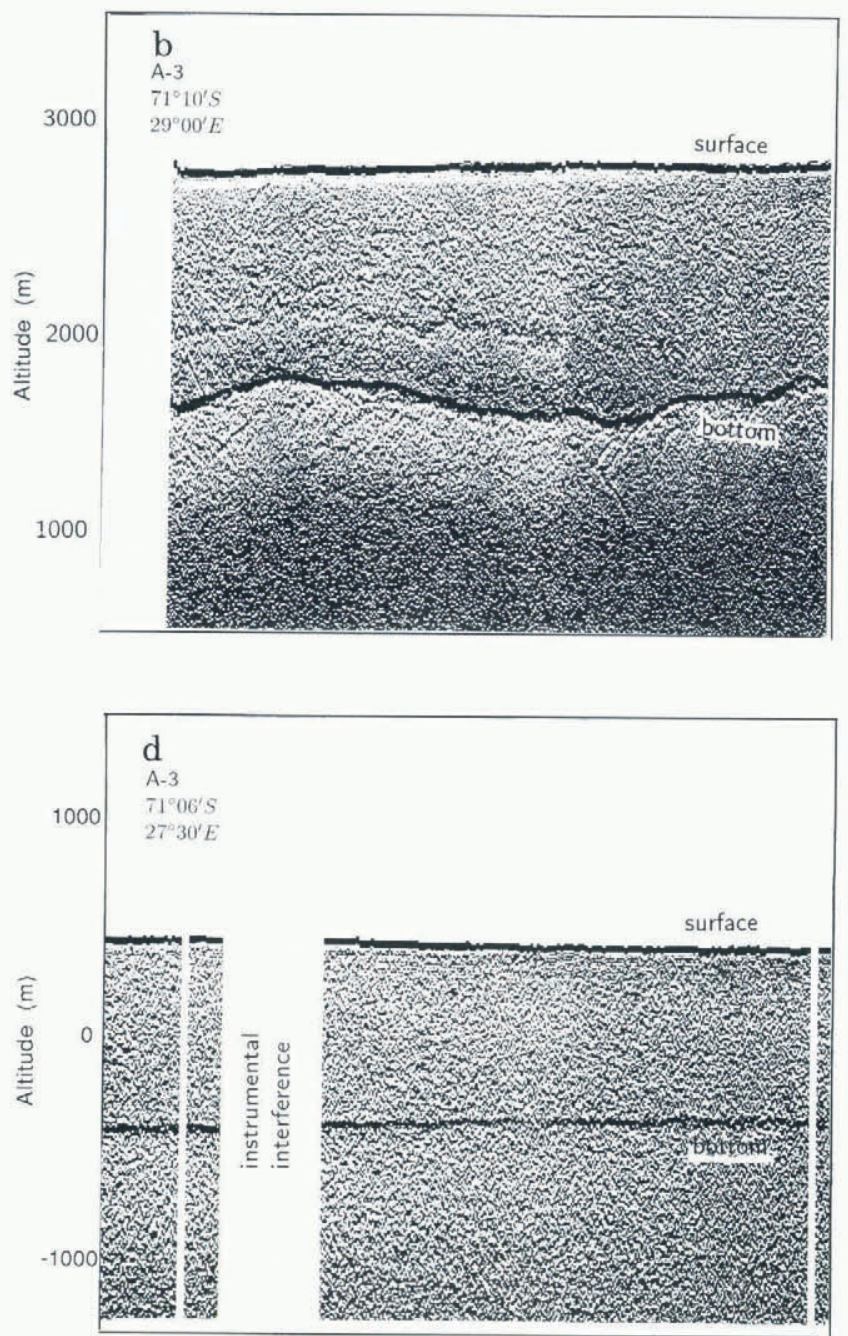

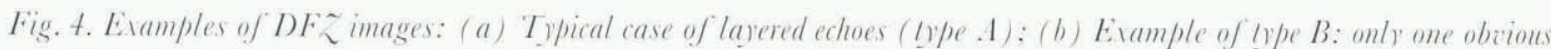
stralified echo is found: (c) . Mulliple echoes appear to have an internal origin. but may be caused by a surface feature (type C): (d) . Vo layered struclure was found (Iype E). Every horizonlal distance in these figures is $14.0 \mathrm{~km}$. Sampled points are shown in Figure 5.

difficult to distinguish the echocs caused by various factors such as surface topography or rocks on the surface. Images affected by instrumental problems for any reason are classified in type D. Instrumental problems occurred when the ice sheet was too shallow to distinguish the surface echo, when the image was obtained with a $60 \mathrm{~ns}$ pulse width which is too short to digitize, when the aircraft was changing direction, or when the aircraft altitude suddenly changed. Finally. we define images where the pattern is random and no apparent layering exists as type E (see Fig. 4d).

After rough surveying using only the image pattern, we examined differences in pulse width and echo strength between all categories except type D. We found, for example, that strong surface echoes sometimes exceed the internal-layered signal level and prevent the internal layering from appearing in the $\mathrm{DF} /$ image. This kind of DF\% image was reclassified as type D. The change from type $\mathrm{A}$ or $\mathrm{B}$ to type $\mathrm{E}$ is very sudden and the signal level becomes weaker. After detailed examination of the echo strength of type E, however, this does not mean that no scattering existed in the internal ice, but only that any layered or structured patterns were not observed. It may be possible to detect layered echoes with different instruments that use different radio frequencies or a finer resolution. The results from along the flight lines are plotted according to the above classification on the topographic map shown in Figure 5 .

\section{Occurrence of layered echo}

From Figure 5, we can see that except for the areas where there was an instrumental type D or surface-feature disturbance type $C$ ) problem, internal echoes are continuously observed in most of the area. However. no lavered echoes are observed at or near the ice shelf. Harrison 1973 reported that the appearance of internallayered echoes was very rare in the Ross Ice Shelf region, but he concluded that this was due to a radar problem. However, no serious instrumental problem occurred during our observation of the ice shelf. The transition from the presence of internal lavers to their absence is very clear along a topographic contour line of about $600 \mathrm{~m}$, which is about $20-30 \mathrm{~km}$ inland from the grounding line.

Internal echoes also failed to appear where flight lines were perpendicular to the inferred flowline, for example. around $21^{\circ} \mathrm{E}, 71^{\circ} 40^{\prime} \mathrm{S}$ (site (e), Fig. 5 and around $22^{\circ} \mathrm{E}$. 


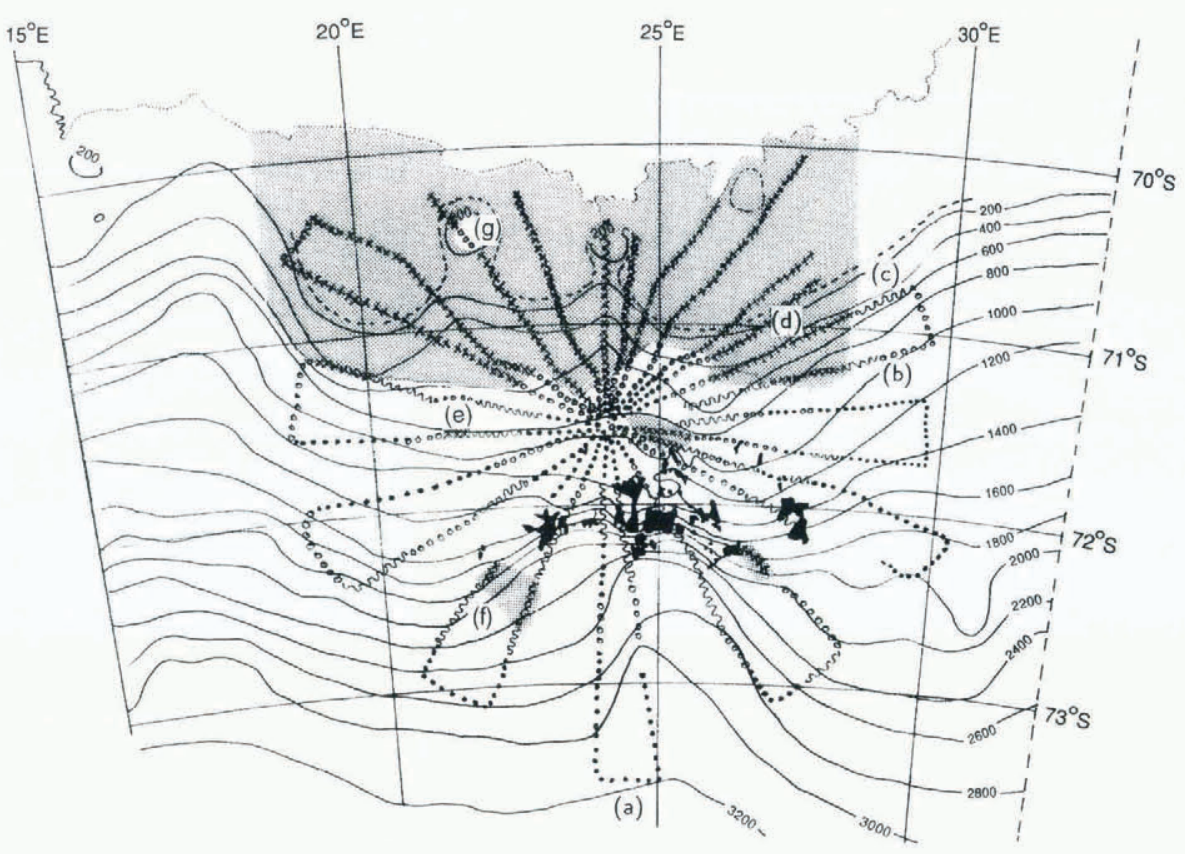

Fig. 5. Map of layered echoes: $\bullet, \circ, \sim$, and $\times$ denote type $A, B, C$ and E, respectively. Type D is shown as a blank. Gray zones represent the area of type E. Sampled points shown in Figure 4 are displayed by $(a),(b),(c)$ and $(d)$.

$72^{\circ} 25^{\prime} \mathrm{S}$ (site (f), Fig. 5). Antennas of the radar system were installed under the wings of the airplane, and the electric-field direction was along the direction of the airplane heading. That is, the antenna polarization of the radar was in the same direction as the flight line.

\section{DISCUSSION}

The boundary between the appearance and the absence of layered echoes is about $20-30 \mathrm{~km}$ inland from the grounding line. Clearly the absence of internal layers is not caused by the influence of sea water, and we have eliminated the possibility of an instrumental problem.

It is interesting that layers at all depths disappear at the same point. If separation of the internal layers is smaller than the radar resolution, which depends on the pulse and beam widths, neighboring peaks will be fused. This is plausible if a tendency towards narrower separation is observed. However, we did not find such a tendency. Observation using different radio frequencies may show a different boundary, but the internal ice change which causes the absence of layered echoes may occur at a point in the inland ice sheet far from the grounding line. Fujita and Mae (1994) proposed that the internal layered echoes are caused by a vertical change in the fabric pattern or acidity. They estimate that scattering due to fabric-pattern change is larger than that due to acidity change at a frequency of $179 \mathrm{MHz}$. The internal-layer echoes secm likely to disappear near the grounding line due to deformation of the fabric. Deformation of the fabric can also occur inland from the grounding line due to other strong forces such as tides.

Internal ice change also causes a polarization effect, as discussed in detail in the next sub-section. Woodruff and Doak (1979) showed that the polarization of radio echoes from the ice-shelf bottom changed between inland and floating ice because of a different propagation effect. They suggest that this difference was caused by the effect of tidal strain on crystal orientation. However, the ice thickness at the grounding line is less than $1000 \mathrm{~m}$ in our case, much smaller than the distance from the grounding line to the boundary line where the echoes stop appearing. Therefore, the difference is difficult to explain by tidal force.

It should be noted that other radar observations of a lower frequency in the ice shelf reported the existence of internal layers (Jacobel and Bindschadler, 1993). Also, it is difficult to explain the isolated internal layer at about $22^{\circ} \mathrm{E}, 75^{\circ} \mathrm{S}$ in our data (site (g), Fig. 5),

\section{Polarization problem}

The region along the line from $26^{\circ} \mathrm{E}, 71^{\circ} 20^{\prime} \mathrm{S}$ to $28^{\circ} \mathrm{E}$, $70^{\circ} 50^{\prime} \mathrm{S}$ (around mark (d), Fig. 5) may also be explained by the polarization effect.

We already suggested in the last paragraph of the previous section that the internal-layer disappearance relates to the angle between the ice-flow direction and polarization of the radar antenna. Fujita and Mae (1993) reported that the internal signal strength depended on the antenna orientation, when using a $179 \mathrm{MHz}$ groundbased radio-echo sounder. Further analysis by Maeno and others (in press) found that the attenuation in ice depended on the antenna direction, and the antenna direction of maximum attenuation was along the flow direction. The above two results were obtained by experiments in which co-polarized antennas were rotated at the same spot. In our case, the tendency of the echo strength is similar to the above results, but is not as clear, since we did not control the antenna orientation at the same point. Controlled experiments are necessary to confirm the relationship between the appearance of layered structure in the radar signal and antenna direction. A theoretical approach may provide useful ideas. Some models are proposed to investigate depolar- 
ization by internal ice layers Woodruff and Doak, 1979; Liu and others, 1994). However, they have no results on the internal layer's appearance.

\section{GONCLUSION}

We examined the basal characteristics near the grounding line using radio-echo-sounding data. The scattering coefficients of the nadir direction changed when very close to the grounding line, the position of which we had previously determined by hydrostatic balance. The difference in scattering strength was due to the different material below the ice and changes in the bottom roughness. In this paper, a clear difference in the smooth-bottom features was detected a few kilometers from the grounding line using radio-echo-sounding data to analyze the incidence-angle dependence of the scattering coefficient. This smoothness that begins at the grounding line seems to be caused by the effect of sea water under the ice sheet. The appearance of double-trip echoes supports this belief. Detecting differences in bottom roughness complements detecting differences in the scattering strength due to different underlying materials. To date, a combination of these methods allows us to determine the position of the grounding line to within a few kilometers. On the other hand, the absences of the internal layer were found in the ice shelf about $20-30 \mathrm{~km}$ inland from the grounding line through the classification of the $\mathrm{DF} \%$ image according to the appearance characteristics of the internal laver and echo strength. This fact suggests the internal change forward ice shelf occur at this point. Another disappearance was found where the antenna polarization is perpendicular to the ice-flow direction. This polarization problem should be theoretically and experimentally examined in detail.

Further investigation is necessary to explain the above results and the mechanism of the internal laver.

\section{ACKNOWLEDGEMENTS}

We thank Professor Y. Naito of the National Institute of Polar Research, Tokyo, who was the leader of JARE-27. We also thank Dr K. Okamoto, Director of the Global Environment Division at the Communications Research Laboratory, Tokyo, for his encouragement, and Dr S. Fujita of Hokkaido University for many stimulating discussions.

\section{REFERENCES}

Fujita, S. and S. Mae. 1993. Relation between ice sheet internal radioecho reflections and ice fabric at Mizuho Station. Antaretica. . Imm. Glaciol., 17, $269-275$

Fujita. S. and S. Mae. 1994. Causes and nature of ice-sheet radio-cho internal reflections estimated from the dielectric properties of ice. Am. Gilaciol.. 20, 80-86.

Harrison, C. H. 1973. Radio echo sounding of horizontal layers in ice. J. Glaciol., 12 66), 383-397

Jacobel. R. W. and R. Bindschadler. 1993. Radar studies in the moutls of Ice Streams D and E, Antarctica. Amu. Glaciol., 17, 262-268.

Jacobel. R. WI., . I. E. Robinson and R. A. Bindschadler. 1994. Studies of the grounding-line location on Ice Streams D and E. Antaretica. Anu. Glaciol., 20. 3942.

Jenkins, A. and C.S. .I. Doake. 1991. Ice ocean interaction on Ronne Ice Shelf, Intarctica. J. Geoplers. Res., 96 (:1 . 791813.

Liu, C.. C.R. Bentles and N.E. Lord. 1994. $c$ axes from radar depolarization experiments at Upstream B Camp, Antaretica, in 1991 92. Amm. Glaciol.. 20, 169176.

Maeno, H., S. Fujita, K. Kamiyama, H. Motoyama, T. Furukatwa and S. Uratsuka. In press. Relation between surface ice llow and anisotropic internal radio-echoes in the Intarctic ice sheet. Proc. IIPR Simp. Polar Meteorol. Cilariol. 9.

Morgan, V. I. 1972. Oxygen isotope evidence for bottom freezing on the Amery lee Shelf, Vature, 2385364 . 393-394.

Neal, C. S. 1979. The dynamies of the Ross Ice Shelf revealed by radio echo-sounding. \%. Gilaciol.. $2490,295-307$.

Nisho. F. and S. Uratsuka. 1991, Subglacial water laycr and grounding line derived from backscattering coeflicients of radio echo sounding in the Shirase Glacier and Roi Baudouin lee Shelf East Intarelica Proc. IIPR Symp. Polar Meteorol. Glaciol. 4, 93102.

Oerter, H. and 6 others. 1992, Evidence for basal marine iee in the Filchere Ronne lee Shell. Valure, 3586385 , $399+01$.

Shabtaic. S.. I. M. Whillans and C. R. Bentes, 1987. The morphology of Iee Streams . A. B. and (: West Intarctica, and their environs, ff Groplems. Res.. 92 B9, 88658883.

Thomas. R. H. 1979. Ior shelves: a review. J. Ciluriol., 2490.273286

Claby. F. T.. R. K. Moore and I. K. Fung, 1982, Micosace remot sensing: aclize and passief. Tol. 2. Reading, M. I. Iddison-llesles Publishing (o.

Cratsukat. S.. F. Nishio, H. Olmate and S. Mae. 1989. Radio scattering characteristics of Antarctic ice shees using airborne radio eche

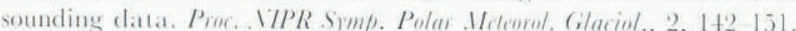

Cratsuka, S.. F. Nishio and S. Mac. 1990. Radio scattering characteristics of the Roi Baudouin Ice Sleflf, East Antarctica. In Murthy. T. K. S.. J. G. Paren. W. M. Sackinger and P. Wadlatms, ds. Io

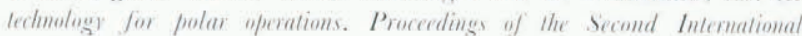

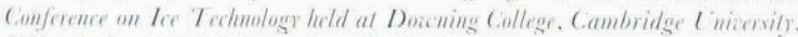
L\%. during 18 20) September 1990. Southampton. Computational Mechanics Publications. 345-351.

Wakahama, G. and II. F. Budd. 1976. Formation of the three-lasered structure of the Amery lee Shelf, Antaretica. J. Glaciol.. 16 74, 295 297.

Woodrult. A. H. W. and C. S. M. Doake. 1979. Depolarization of radio wates can distinguish between floating and grounded ice sheets. J Glaciol., $2389,223232$. 